\title{
Source Complexity of the 1988 Armenian Earthquake: Evidence for a Slow After-Slip Event
}

\author{
MASAYUKI KIKUCHI \\ Department of Physics, Yokohama City University, Yokohama, Japan \\ HIROO KANAMORI \\ Seismological Laboratory, Califormia Institute of Technology, Pasadena \\ KENII SATAKE \\ Department of Geological Sciences, University of Michigan, Ann Arbor

\begin{abstract}
We analyzed teleseismic $P$ and $S$ waves using a multiple-event deconvolution method to investigate the source process of the Spitak, Armenia, earthquake of December 7, 1988. Teleseismic long-period body waves exhibit complex waveforms, significantly more complex than those normally seen for an event of this size. We identified two groups of subevents. One is a group of strike-slip events during the first $20 \mathrm{~s}$. The other is a dip-slip event initiating at about $30 \mathrm{~s}$ after the initial rupture. The tensor sum of all the subevents is essentially strike-slip (strike $=302^{\circ}, \operatorname{dip}=59^{\circ}$, rake $=143^{\circ}$ ) with a scalar moment of $1.47 \times 10^{19} \mathrm{~N} \mathrm{~m}$. The seismic moment of the dip-slip event $\left(\right.$ strike $=89^{\circ}$, dip $=60^{\circ}$, rake $=88^{\circ}$ ) is $5.6 \times 10^{18} \mathrm{~N} \mathrm{~m}$, nearly $40 \%$ of the total, and the moment release rate is slower than the other subevents with a strike-slip mechanism. We call this event a slow after-slip event. The mechanism of the after-slip event is consistent with the present-day deformation pattern in the Caucasus where north-south compression is predominant due to the continental collision between the Arabian plate and the Russian Platform. This result suggests that in a region where both strike slip motion and crustal shortening are taking place, like southem Califomia, a large strike-slip event may accompany large thrust events and vice versa. In order to determine the total coseismic deformation pattern, it is essential to resolve these multiple events in time, space, and mechanism.
\end{abstract}

\section{INTRODUCTION}

The Spitak, Armenia, earthquake of December 7, 1988, is one of the most devastating earthquakes in recent years. Source parameters given by the National Earthquake Information Center (NEIC) are origin time, 0741:24.9 UT, location, $40.94^{\circ} \mathrm{N}, 44.29^{\circ} \mathrm{E}$; depth, $10 \mathrm{~km}$ and $M_{s}=6.8$. Despite its moderate size, it caused the largest earthquake disaster since the 1976 Tangshan earthquake in China. Surface breaks were traced over a distance of $13 \mathrm{~km}$ in the epicentral region. They showed a reverse slip of about 1.6 $m$ with a considerable amount of strike-slip component. Aftershock activity extended over an area of about $300 \mathrm{~km}^{2}$ [Cisternas et al., 1989].

Teleseismic long-period body waves exhibit complex waveforms, significantly more complex than those normally seen for an event of this size. Pacheco et al. [1989] used broadband and long-period records to investigate the details of the source process. They identified three subevents during the first $20 \mathrm{~s}$ and related them to the field observations such as surface breaks and aftershock distribution. Their analysis was focused on the first $20 \mathrm{~s}$ of the rupture process. In this study we focus our attention on the later part of the records where significant phases are seen. Since source complexity may have an important

\section{Copyright 1993 by the American Geophysical Union.}

Paper number 93JB01568.

0148-0227/93/93JB-01568\$05.00 bearing on the destructive power of an earthquake and on the pattern of coseismic deformation in complex tectonic environments, we made an extensive analysis of teleseismic body waves using a newly developed multiple-event deconvolution method.

We will show that the Armenian earthquake involved a large (about $40 \%$ of the total moment) secondary event which occurred about $30 \mathrm{~s}$ after the beginning of the earthquake. This event has a north-south compression thrust mechanism with slower moment release rate than the primary strike-slip events.

\section{PRELIMINARY ANALYSIS}

Since the analysis of multiple events is very complex, it is instructive to investigate the overall characteristics of the data before embarking on inversion.

We used teleseismic $P$ and $S H$ waves from stations of the Global Digital Seismograph Network (GDSN), the China Digital Seismograph Network (CDSN), the Incorporated Research Institutions for Seismology (IRIS), and GEOSCOPE. The station coverage is shown in Figure 1. The station coverage is good in the northern hemisphere, but only one station is located in the southwest quardrant. To determine the $P$ and $S$ wave arrival times, we first referred to the Jeffreys-Bullen [Jeffreys and Bullen 1958] travel time table, and then adjusted the onset times within a few seconds to account for the variations of travel times due to the lateral heterogeneities of the Earth. Table 1 lists the station parameters and the $P$ and $S H$ phases used in the analysis. 


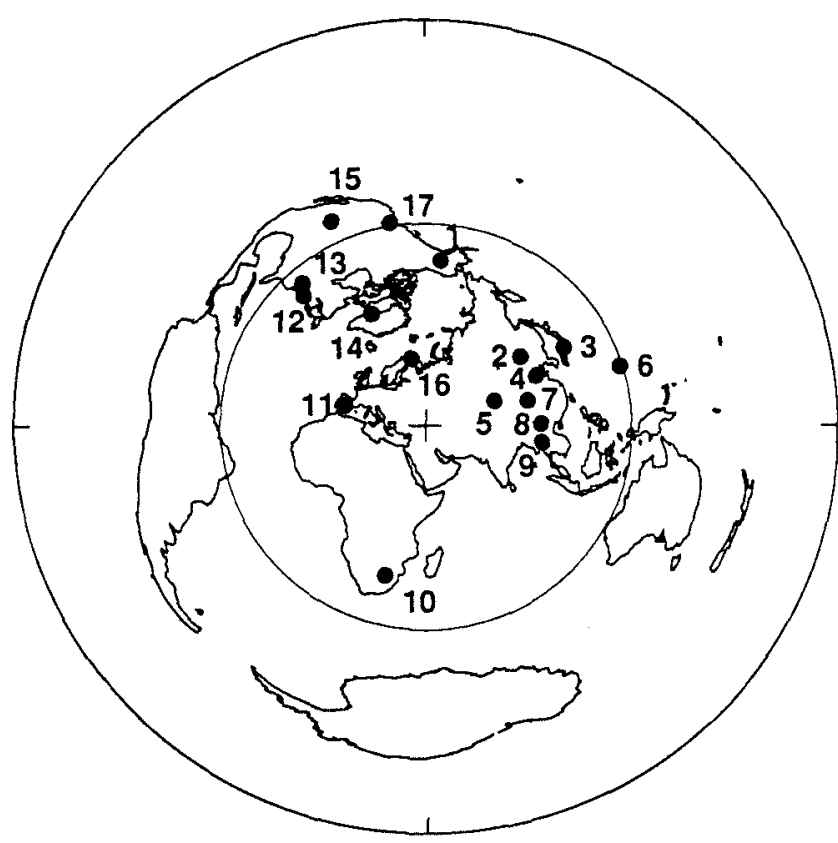

Fig. 1. Seismic stations used in the analysis (equal-distance projection). The smaller and larger circles indicate epicentral distances of $90^{\circ}$ and $180^{\circ}$, respectively. The numbers refer to those in Table 1 .

These records were originally recorded with seismographs having different responses. The IRIS and GEOSCOPE networks have a broadband flat velocity response over a wide frequency range, while the GDSN long-period response has a relatively narrow passband around a period of 10-50 s.

Broadband records contain detailed information about the source process. However, since they also contain complex phases caused by the structures near the source and stations, they usually look very complex. We need detailed knowledge about the structures to extract useful information about the source. On the other hand, long-period narrowband records do not carry detailed source information, but they are relatively insensitive to the details of the structures and are more easily interpretable by visual inspection.

Since the records with different responses exhibit different appearances and are difficult to interpret visually, we first equalized the response of the records to facilitate visual inspection. Figure $2 a$ shows examples of broadband $P$ and
SH ground-motion displacements computed from the original velocity records. The start time of each record is set at $10 \mathrm{~s}$ before the Jeffreys-Bullen time. Figure $2 b$ shows the records equalized with the long-period response of the station ANMO. These records are hereafter referred to as "ANMO response data." Figure $2 c$ shows a similar set of records which are equalized with the long-period response of the station BJI. This set is referred to as "BJI response data." The bandwidth (the frequency range over which the gain is higher than $1 / 2$ of the peak response) of the ANMO instrument is from 13 to $50 \mathrm{~s}$, while that of the BJI instrument is from 25 to $50 \mathrm{~s}$.

On the ANMO response data, a significant phase can be seen on the vertical component at about $40 \mathrm{~s}$ after the initial arrival. This phase, indicated by shading in Figure $2 b$, is consistently seen on the $P$ wave records for all the stations (Figure 2d). This phase is also seen on the broadband records (Figure $2 a$ ), though it is less distinct than on the ANMO data. The $S H$ component, however, does not show this phase distinctly.

This later phase could be a second event or a phase produced by reflections at some structural boundaries during the propagation path. The latter is very unlikely because there is no obvious reflector that can generate a large phase delayed by more than $40 \mathrm{~s}$. If the epicenter is beneath the seafloor, such a later phase could be produced by reverberations of $P$ waves within the water layer. In this paper we will examine whether this later phase can be consistently explained with a late subevent. The mechanism of the subevent must be such that it generates $P$ waves more efficiently than it does $S H$ waves.

First, we examine the spectral structure of the observed $P$ and $S H$ waves. We computed the power spectra of all the records and averaged them. Then we corrected for the difference in attenuation between $P$ and $S H$ waves. We multiplied the spectrum of $S H$ wave by a factor

$$
\exp \left[2 \pi f\left(t_{s}^{*}-t_{p}^{*}\right)\right]
$$

where $t_{p}^{*}$ and $t_{s}^{*}$ are the attenuation time constants for $P$ and $S$ waves, respectively. We used $1 \mathrm{~s}$ and $4 \mathrm{~s}$ for $t_{p}^{*}$ and $t_{s}^{*}$, respectively. Figure $3 a$ shows the spectra of broadband $P$ and $S H$ waves thus obtained. The two spectra are similar except for the frequency range higher than about $100 \mathrm{mHz}$.

TABLE 1. List of Station Parameters

\begin{tabular}{|c|c|c|c|c|c|c|c|}
\hline & Station & Network & Azimuth, deg & Back Azimuth, deg & Distance, deg & Phase & Weight \\
\hline 1 & COL & GDSN & 5.3 & 350.6 & 73.7 & $P, S H$ & $1.0,0.2$ \\
\hline 2 & HIA & CDSN & 53.6 & 291.3 & 51.7 & $P, S H$ & $1.0,0.2$ \\
\hline 3 & INU & GEO & 60.4 & 306.4 & 69.6 & $P, S H$ & $1.0,0.2$ \\
\hline 5 & WMQ & CDSN & 70.1 & 280.3 & 31.9 & $P, S H$ & $0.1,0.05$ \\
\hline 6 & GUMO & GDSN & 72.8 & 312.1 & 89.0 & $P$ & 1.0 \\
\hline 7 & $\mathrm{LZH}$ & CDSN & 75.8 & 295.1 & 46.0 & $P, S H$ & $1.0,0.2$ \\
\hline 8 & KMI & CDSN & 89.2 & 303.5 & 50.6 & $P, S H$ & $1.0,0.2$ \\
\hline 9 & CHTO & GDSN & 98.4 & 307.9 & 51.5 & $P$ & 1.0 \\
\hline 10 & SLR & GDSN & 195.4 & 12.9 & 68.3 & $P, S H$ & $3.0,0.6$ \\
\hline 11 & TOL & GDSN & 284.5 & 72.2 & 36.2 & $P, S H$ & $1.0,0.2$ \\
\hline 12 & $\mathrm{HRV}$ & IRIS & 317.3 & 44.0 & 78.4 & $P, S H$ & $1.0,0.2$ \\
\hline 13 & SCP & GDSN & 319.7 & 40.2 & 82.8 & $P, S H$ & $1.0,0.2$ \\
\hline 14 & GDH & GDSN & 334.5 & 66.4 & 54.7 & $P, S H$ & $1.0,0.2$ \\
\hline 15 & ANMO & GDSN & 336.0 & 22.0 & 99.4 & $P$ & 0.1 \\
\hline 16 & $\mathrm{KEV}$ & GDSN & 348.2 & 153.6 & 30.1 & $P$ & 0.05 \\
\hline
\end{tabular}




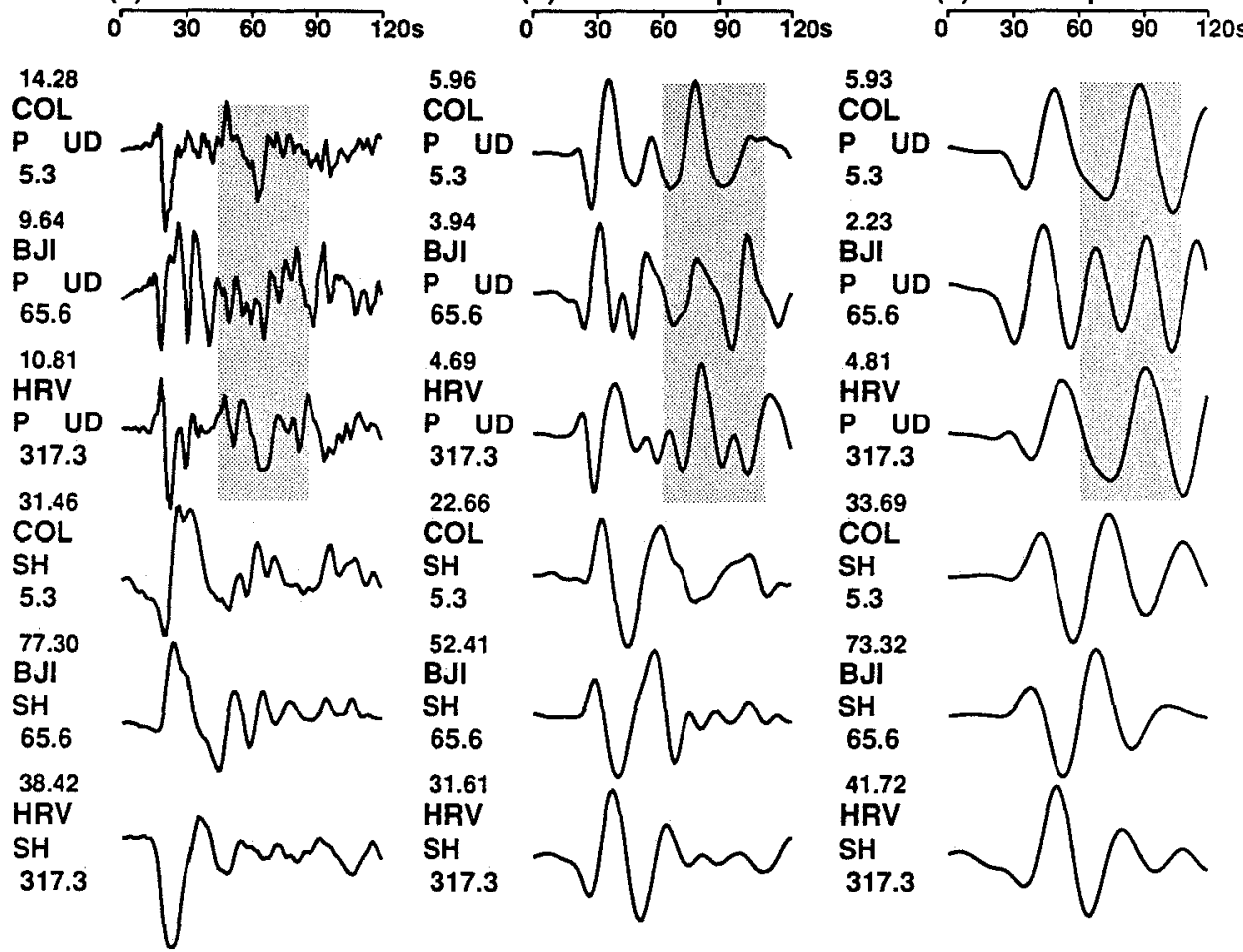

(d) ANMO Response

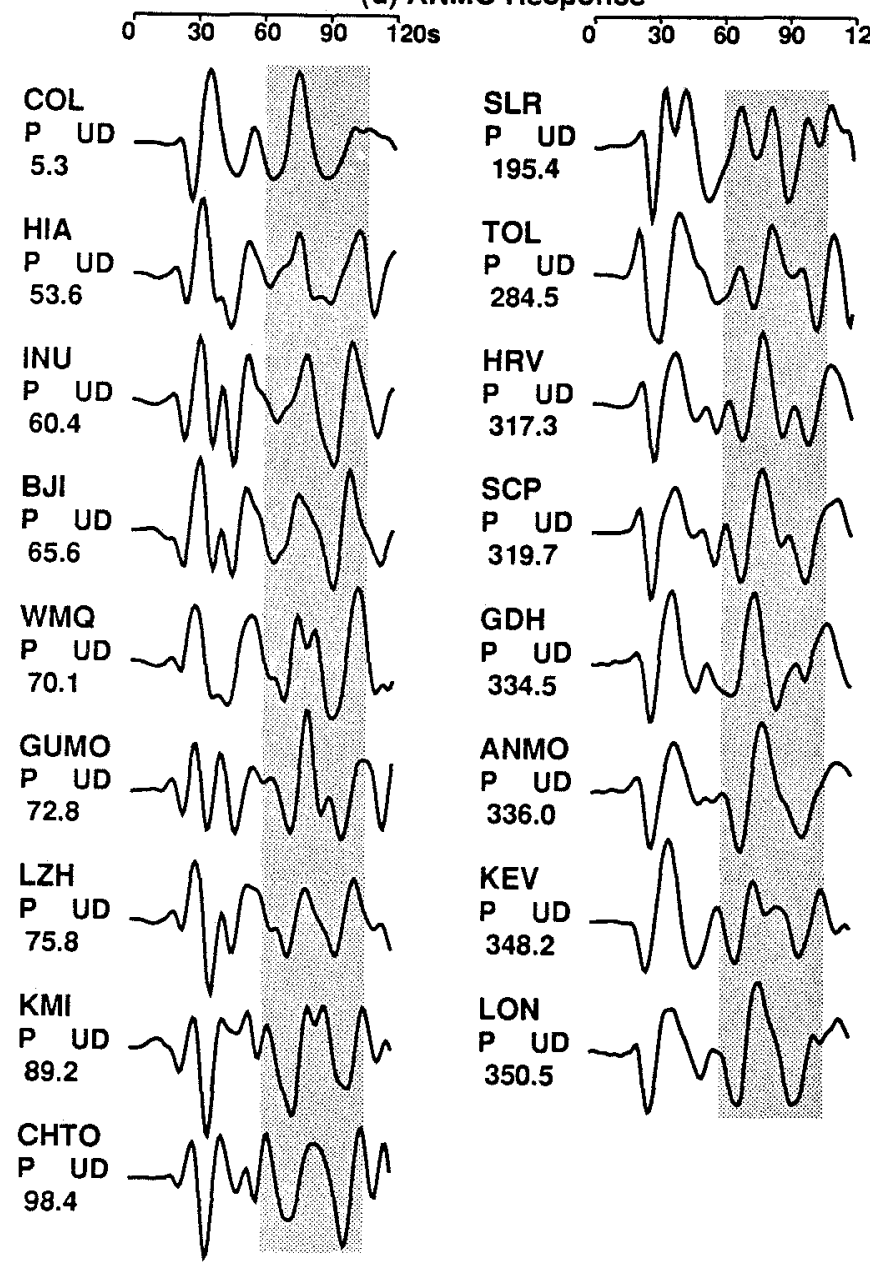

Fig. 2. (a) Examples of broadband records converted to ground displacement. The number above the station code indicates peak-to-peak amplitude in microns. The number below the phase code $(P / S H)$ and component indicates the station azimuth. Hatching indicates the phase arriving at about $40 \mathrm{~s}$ after the beginning. (b) Examples of ANMO response data.The records are equalized with the response of the long-period instrument at ANMO station. Hatching indicates the phase arriving at about $40 \mathrm{~s}$ after the beginning. (c) Examples of BJI response data. The records are equalized with the response of the long-period instrument at BJI. (d) $P$ waves recorded with the ANMO response. Hatching indicates the phase arriving at about $40 \mathrm{~s}$ after the beginning. 
(a) Broadband

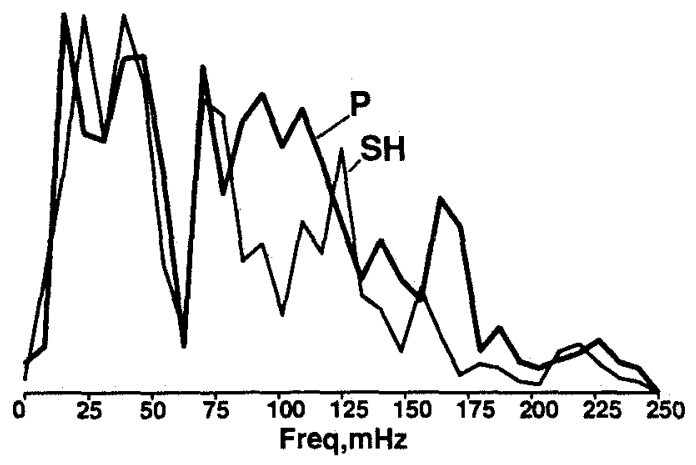

(b) ANMO Response

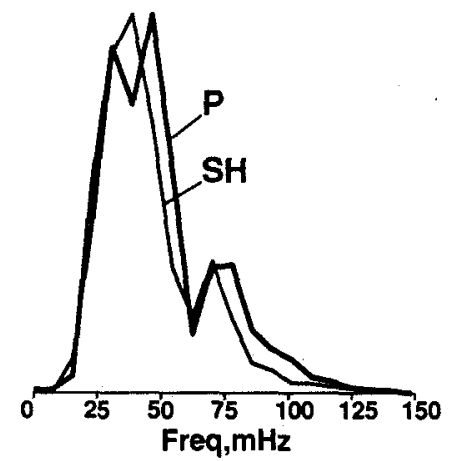

(c) BJI Response

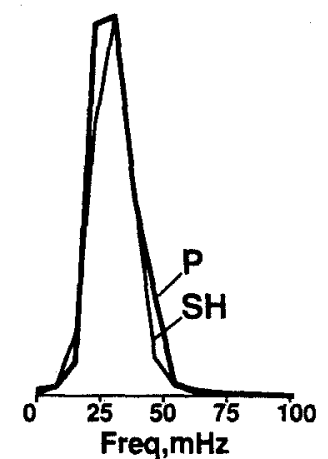

Fig. 3. (a) Comparison of the average spectrum of broadband $P$ waves and $S H$ waves. (b) The average spectra of $P$ and $S H$ waves of the ANMO response data. (c) The average spectra of $P$ and $S H$ waves of the BJ response data. The difference in attenuation between $P$ and $S H$ waves is removed. Freq is frequency.

A sharp notch at $62.5 \mathrm{mHz}$ suggests a characteristic source time of $16 \mathrm{~s}$. The mismatch between $P$ and $S H$ wave spectra in the high-frequency range is probably due to source complexity and unknown structure effects.

Figures $3 b$ and $3 c$ show the power spectra of the ANMO and BJI response data. For the ANMO response the highfrequency components are suppressed compared with those for the broadband records because of the instrument response and, consequently, the $P$ and $S H$ wave spectra are similar to each other in the pass-band. For the BJI response data, the passband is too narrow to show the characteristic notch at $62.5 \mathrm{mHz}$ in the power spectrum.

This comparison suggests that the ANMO response data are most suitable for examining the overall feature of the source process, and we will mainly use this data set in the following analysis. The sampling interval of the ANMO response data is $1 \mathrm{~s}$. We used a 120 -s-long window following the initial $P$ arrival for waveform inversion.

\section{ANALYSIS}

\section{Method}

We employed an iterative deconvolution method developed by Kikuchi and Kanamori [1986, 1991] this method allows mechanism changes during the rupture sequence. Here we describe the method only briefly. A source process is represented as a sequence of subevents, each specified by a moment tensor and its onset time and location. The moment tensor is then represented by a linear combination of elementary moment tensors defined by Kikuchi and Kanamori [1991]: $\left\{M_{n}\right.$, where $\left.n=1, \ldots, N_{b}\right\}$. The number of the elementary tensors, $N_{b}$, varies from two to six depending on the constraint to be imposed on the mechanism. In the most general case that includes an isotropic component, $N_{b}=6$; in case of a double-couple, $N_{b}$ $=5$, with the constraint of vanishing determinant.

\section{Grid Scheme and Green's Functions}

The first step involves computation of Green's functions for elementary moment tensors in a layered structure. Table 2 shows the structures at the source and receiver sites used to compute Green's functions. The near-source structure is the same as that used by Pacheco et al. [1989] and the nearreceiver structure is a standard one used by Jeffreys and Bullen [1958]. We used $Q$ filters with the attenuation time constant $t_{p}^{*}=1 \mathrm{~s}$ for $P$ waves and $t_{s}^{*}=4 \mathrm{~s}$ for $S H$ waves. The source and receiver functions were computed using Haskell's

TABLE 2. Structures

\begin{tabular}{cccc}
\hline$\alpha, \mathrm{km} / \mathrm{s}$ & $\beta, \mathrm{km} / \mathrm{s}$ & $\rho, \mathrm{g} / \mathrm{cm}^{3}$ & Thickness, $\mathrm{km}$ \\
\hline \multicolumn{4}{c}{ Source Structure } \\
4.00 & 2.14 & 2.35 & 1.0 \\
5.60 & 3.23 & 2.70 & 5.0 \\
6.50 & 3.75 & 2.85 & 30.0 \\
8.10 & 4.68 & 3.30 & $\ldots$ \\
5.57 & & Receiver Structure & \\
6.50 & 3.36 & 2.65 & 15.0 \\
8.10 & 3.74 & 2.87 & 18.0 \\
\hline
\end{tabular}


propagator matrix in the way described by Bouchon [1976] and Haskell [1960, 1962].

We set up grid points only within the third layer $(\alpha=6.5$ $\mathrm{km} / \mathrm{s}$ ) because the details of the structure are not known. With the sampling interval of $1 \mathrm{~s}$, the minimum depth increment to be resolved by depth phases such as $p P$ and $s P$ is 2 to $3 \mathrm{~km}$. Thus we took three planes at three discrete depths of $7.5,10.0$, and $12.5 \mathrm{~km}$. This particular grid structure, however, does not seriously affect the inversion results. For sources in the upper two layers, the calculated Green's function has a slightly smaller amplitude but about the same waveform over the frequency band of our analysis. On each plane, seven grid points are distributed in a $\mathrm{N} 65^{\circ} \mathrm{W}$ $\mathrm{S} 65^{\circ} \mathrm{E}$ direction at equal spacings of $10 \mathrm{~km}$, as shown in Figure 4. Let $x_{j}(t)$ denote the $j$ th observed record and $w_{j n}(t$; $p$ ) denote the Green's functions due to the $n$th elementary moment tensor $M_{n}$, where $p$ is a parameter that collectively represents the onset time and the location of the subevent. Then the synthetic wave $y_{j}(t ; p)$ due to a moment tensor

$$
M_{i j}=\sum_{n=1}^{N_{b}} a_{n} M_{n}
$$

is given by

$$
y_{j}(t ; p)=\sum_{n=1}^{N_{b}} a_{n} w_{j n}(t ; p)
$$

The coefficients $a_{n}$ and the parameter $p$ are determined with the least squares criterion:

$$
\Delta=\sum_{j=1}^{N_{s}} \int\left[x_{j}(t)-\sum_{n=1}^{N_{b}} a_{n} w_{j n}(t ; p)\right]^{2} d t=\min
$$

and with a grid search for $p$ to maximize the correlation function between the observed and synthetic waveforms:

$$
\Psi(p)=\frac{\sum_{j=1}^{N_{s}} \int\left[x_{j}(t) y_{j}(t ; p)\right] d t}{\sum_{j=1}^{N_{s}} \int\left[x_{j}(t)\right]^{2} d t}
$$

where $N_{s}$ is the number of seismograms used.

\section{Station Weighting}

In equations (3) and (4), we applied station weighting factors to both the observed and synthetic waveforms considering the azimuthal coverage and the quality of the observed records. The factors are given in Table 1. The large weighting factor for SLR is to compensate for the poor azimuthal coverage in the southern azimuth.

\section{Trade-Off Between Timing and Mechanism}

The model parameter $p$ represents the timing $\tau$, the location $l$ along the strike, and the depth $h$. In this analysis, we extensively used the $\tau$ - $l$ diagram described by Kikuchi and Kanamori [1991]. First, a subevent is placed on grid points on the $(\tau-l)$ plane; the correlation given by (4) is computed, and the resulting mechanism is plotted on

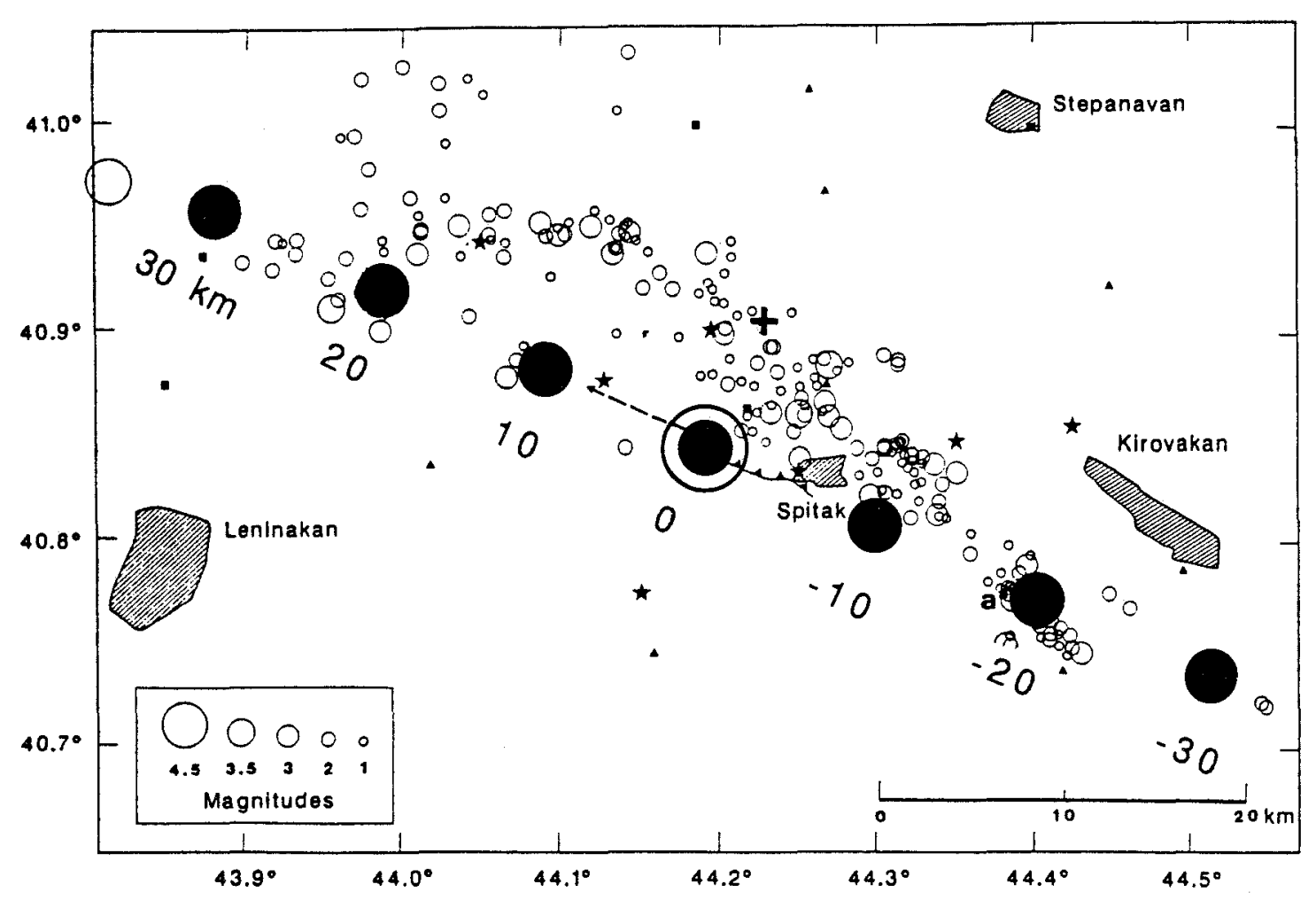

Fig. 4. Grid scheme for inversion. Seven grid points are set up at equal spacings of $10 \mathrm{~km}$ on a line with a strike of $\mathrm{N} 65^{\circ} \mathrm{W}$. 
the grid point on the $\tau-l$ diagram. In these computations we used a symmetric trapezoidal source time function with a rise time of $3 \mathrm{~s}$ and the total duration of $8 \mathrm{~s}$ (see inset of Figure $5 a$ ). This time function was used throughout the initial iterations. Figure $5 a$ shows the contour map of the correlation function $\Psi(\tau, l, h=10 \mathrm{~km})$ on the $(\tau-l)$ plane for the base system of double-couple. The solid stepladder pattern represents the rupture front with a rupture velocity of $3 \mathrm{~km} / \mathrm{s}$. We assumed that no subevents are located on the $\tau$. $l$ plane behind this rupture front. Figure $5 b$ shows the best fit double-couples placed at grid points $10 \mathrm{~km}$ apart in space and $10 \mathrm{~s}$ in time. The mechanism of the best fit subevent within each $10 \mathrm{~s}$ interval is shown in the middle of the interval (e.g., the mechanisms shown at $\tau=5 \mathrm{~s}$ indicate the mechanisms of the best fit subevent during the time interval from 0 to $10 \mathrm{~s}$ ).

The trade-off between the timing and the focal mechanism of subevents is clearly displayed. The highest correlation occurs at about $\tau=4 \mathrm{~s}$, suggesting that the first subevent is located near $\tau=4 \mathrm{~s}$, and $l=0$ to $10 \mathrm{~km}$. A relatively high correlation is seen at about $\tau=18 \mathrm{~s}$ with a subevent having a mechanism almost opposite to the first subevent. As shown in the following discussion, this correlation is an artifact caused by the trade-off between the onset time and the mechanism discussed in detail by Kikuchi and Kanamori [1991]. We then computed the residual waveform by subtracting the synthetic waveform computed for the first subevent from the observed waveform, and we computed correlations. As Figure $6 a$ shows, the highest correlation now appears at about $\tau=10 \mathrm{~s}$ and $l=20 \mathrm{~km}$ with a subevent having a right-lateral mechanism on the N65 W-S $65^{\circ} \mathrm{E}$ trend. We take this to be the second subevent. Although the relatively high correlation at $\tau=18 \mathrm{~s}$ is still visible, the correlation at $\tau=10 \mathrm{~s}$ is much higher. We then subtracted the synthetic waveform for the second subevent from the residual waveform, and we repeated the procedure. As Figure $7 a$ shows, no more significant correlation was found during the first $30 \mathrm{~s}$. However, Figures 5, 6, and 7 all show a high correlation at $\tau=45 \mathrm{~s}$ and $l=30 \mathrm{~km}$ with a thrust subevent. This event is especially distinct on Figure 7 . We consider it to be the third subevent. Figure $7 a$ shows a high correlation at $\tau=60 \mathrm{~s}$ with a normal-fault mechanism, but the correlation disappeared when the synthetic for the third event was subtracted from the residual waveform. Figure $7 a$ indicates
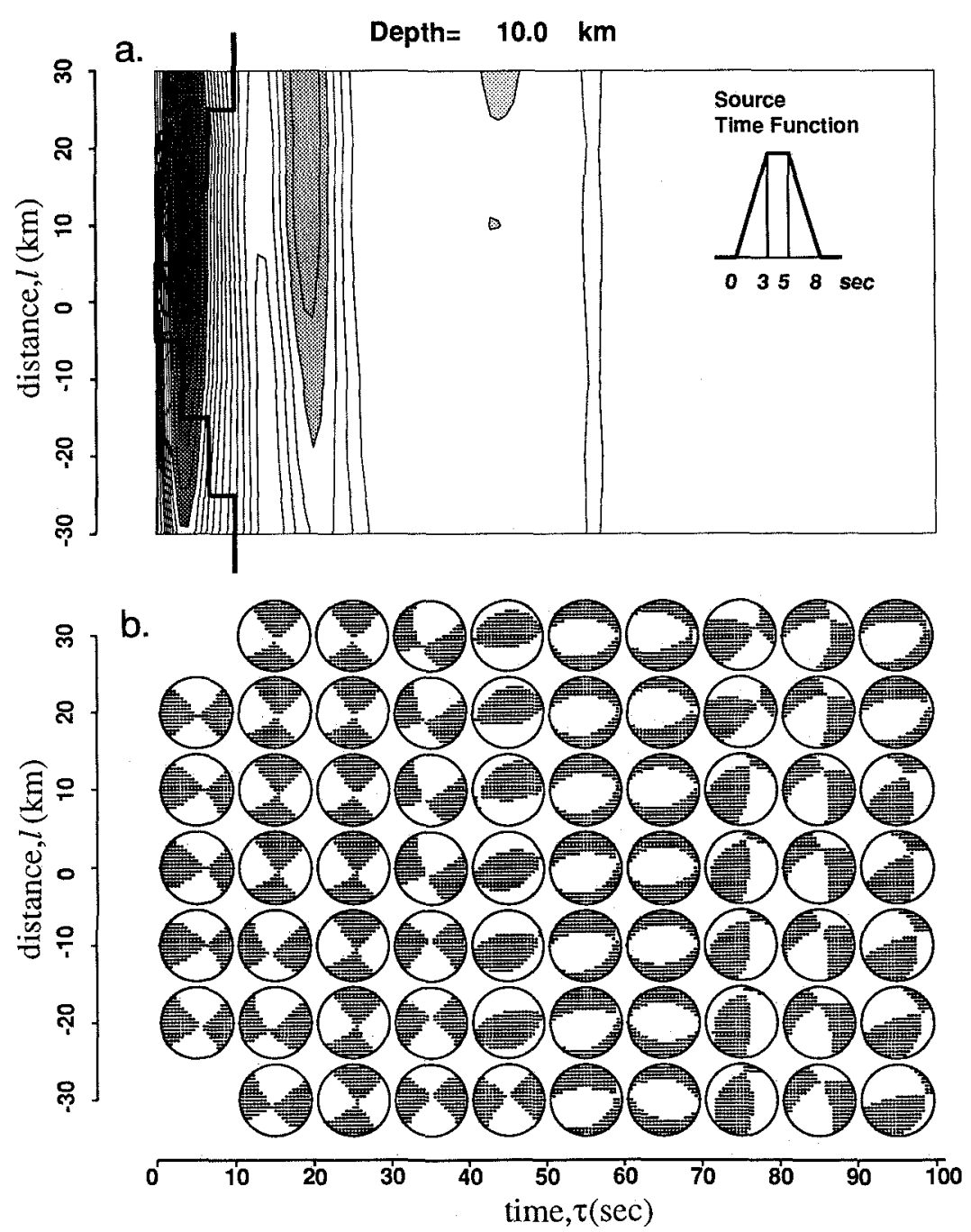

Fig. 5. Correlation diagrams for the observed records. (a) Contour map of the correlation function in the base system of general double-couple. The maximum value of correlation $(\Psi=0.37)$ is shown by the fifteenth contour line. (b) Best fit double-couples at grid points for every $10 \mathrm{~s}$. The solid stepladder pattem represents the rupture front with a velocity of 3 $\mathrm{km} / \mathrm{s}$. 

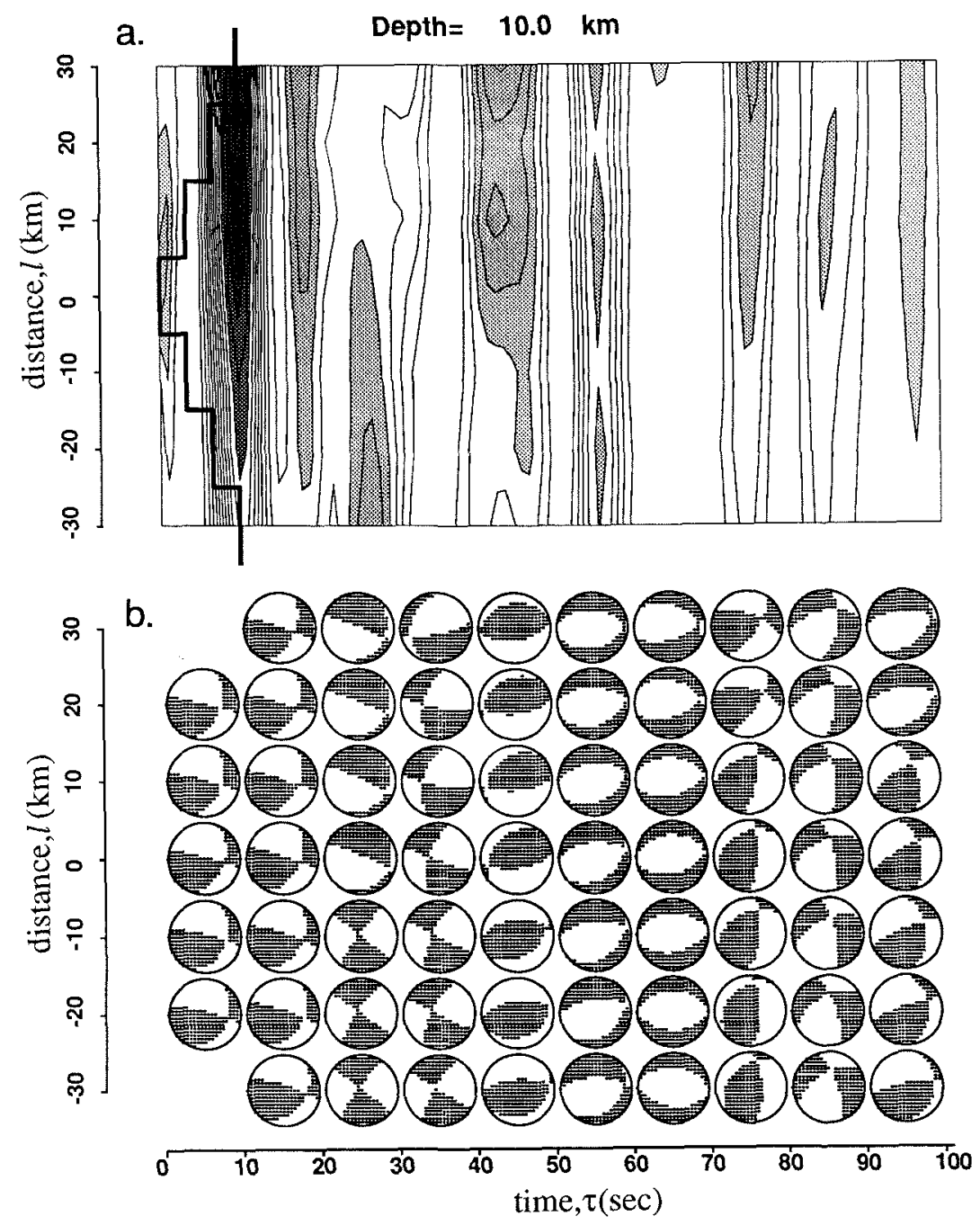

Fig. 6. Correlation diagrams for the first residual records. (a) Contour map of the correlation function in the base system of general double-couple. The maximum value of correlation $(\Psi=0.12)$ is shown by the fifteenth contour line. $(b)$ Best fit doublecouples at grid points for every $10 \mathrm{~s}$.

another subevent at $\tau=80 \mathrm{~s}$, but it is a relatively small event.

Since the analysis of multiple events is very complex, some judgments are inevitably needed to determine the sequence of subevents. The use of correlation diagrams shown in Figures 5, 6, and 7 facilitates the analysis while providing graphical aids in making the judgments. Although Figures 5, 6, and 7 are for only one depth, $10 \mathrm{~km}$, the correlation diagrams for other depths, 7.5 and $12.5 \mathrm{~km}$, were also consulted in determining the event sequence.

The third thrust event at $\tau=45 \mathrm{~s}$ is a robust feature that consistently resulted from inversion regardless of the choice of the preceding events; hence we consider it a real feature of this sequence. Similarly the fourth strike-slip event at $\tau=80 \mathrm{~s}$ is a robust feature.

At the fourth iteration, the normalized residual error defined by

$$
\bar{\Delta}=\Delta / \sum_{j=1}^{N_{s}} \int\left[x_{j}(t)\right]^{2} d t
$$

is 0.43 . Further iterations did not decrease the value of $\bar{\Delta}$ significantly $(\bar{\Delta}=0.39$ and 0.37 at the fifth and sixth iterations, respectively.) Thus we chose the first four sources for the constituent subevents of the coseismic rupture process, and we redetermined the individual source time functions by the method described in the following section.

\section{FINAL RESULTS}

After the subevent sequence was determined, we fixed the mechanism and location of the subevents, and we relaxed the constraint that all the subevents have the same source time function. We represent the source time function by superposition of narrow triangle source functions. We used isosceles triangle functions with a base width of $6 \mathrm{~s}$ and distributed them at an equal interval of $3 \mathrm{~s}$ around the onset time of each subevent determined with the iteration procedure (Figure 8). Then the heights of the triangles, $m_{1}$, $m_{2}, \cdots$ were determined with the linear least squares method with the positivity constraint on the height. The final 

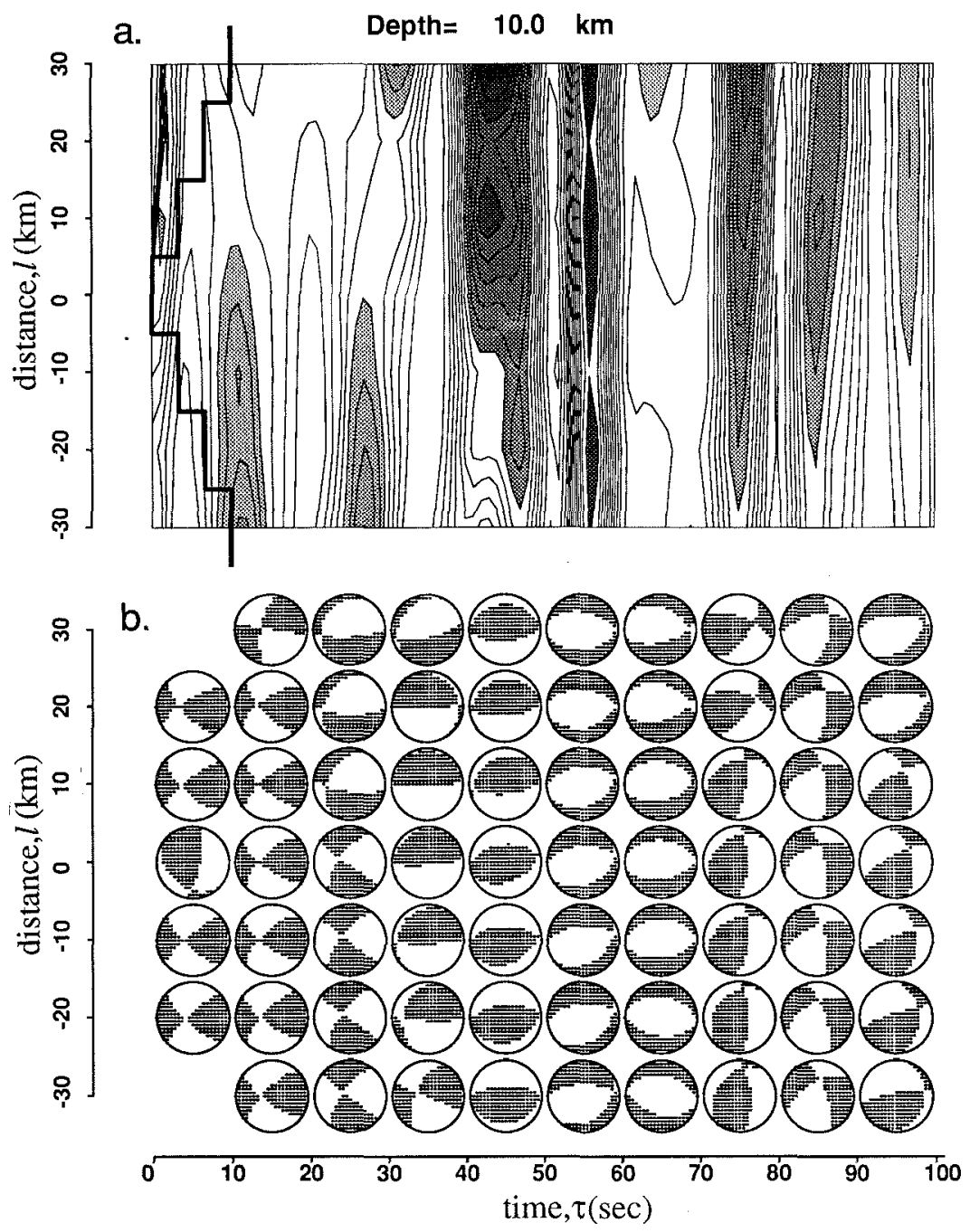

Fig. 7. Correlation diagrams for the second residual records.

(a) Contour map of the correlation function in the base system of general double-couple. The maximum value of correlation $(\Psi=0.05)$ is shown by the fifteenth contour line.

(b) Best fit double-couples at grid points for every $10 \mathrm{~s}$.

solution is shown in Figure 9. The mechanisms of the four subevents shown in Figure 9 are those determined by the iteration described above. The source parameters are given in Table 3. In Figure 10 the synthetic waveforms for the final model are compared with the observed ones. The waveform match is good at all stations except TOL. The results are summarized as follows.

1. The tensor sum of all the subevents is essentially strike-slip with a significant nondouble-couple component. The scalar moment is $1.47 \times 10^{19} \mathrm{~N} \mathrm{~m}$. The moment tensor components are given in Table 4 . The nondouble-couple component $\varepsilon$ defined by the ratio of the smallest (in absolute sense) eigenvalue to the largest (in absolute sense), is 0.15 .

2. There are two groups of subevents. One is a group of strike-slip events during the first $20 \mathrm{~s}$ (subevents 1 and 2). The effective rupture duration is $19 \mathrm{~s}-4 \mathrm{~s}=15 \mathrm{~s}$. The other is a dip-slip event initiating at about $30 \mathrm{~s}$ after the initial break (subevent 3). The seismic moment is $5.6 \times 10^{18} \mathrm{~N} \mathrm{~m}$, nearly $40 \%$ of the total. The effective rupture duration is $59 \mathrm{~s}$ $-32 \mathrm{~s}=27 \mathrm{~s}$, somewhat longer than that of the initial strike-slip fault. Subevent 4 is similar in mechanism to the first group and may be considered an after-slip event which occurred on the fault where the initial rupture occurred.

3. The rupture propagates westward, although the resolution of source location is not high.

This result can be compared with that of the centroid moment tensor (CMT) inversion we made using long-period surface waves recorded on IRIS and GDSN stations.

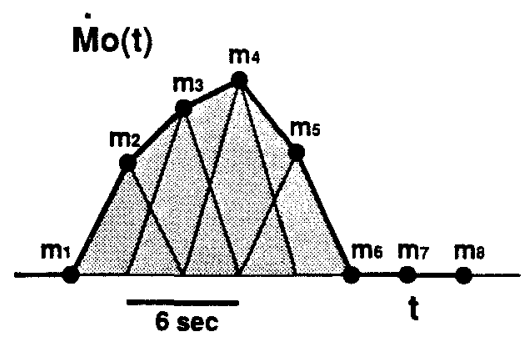

Fig. 8. Parameterization of the source time function $\dot{M}_{0}(t)$ with isosceles triangle functions. The heights of the triangles, $m_{1}, m_{2}, \cdots$ are determined with the linear least squares methods. 

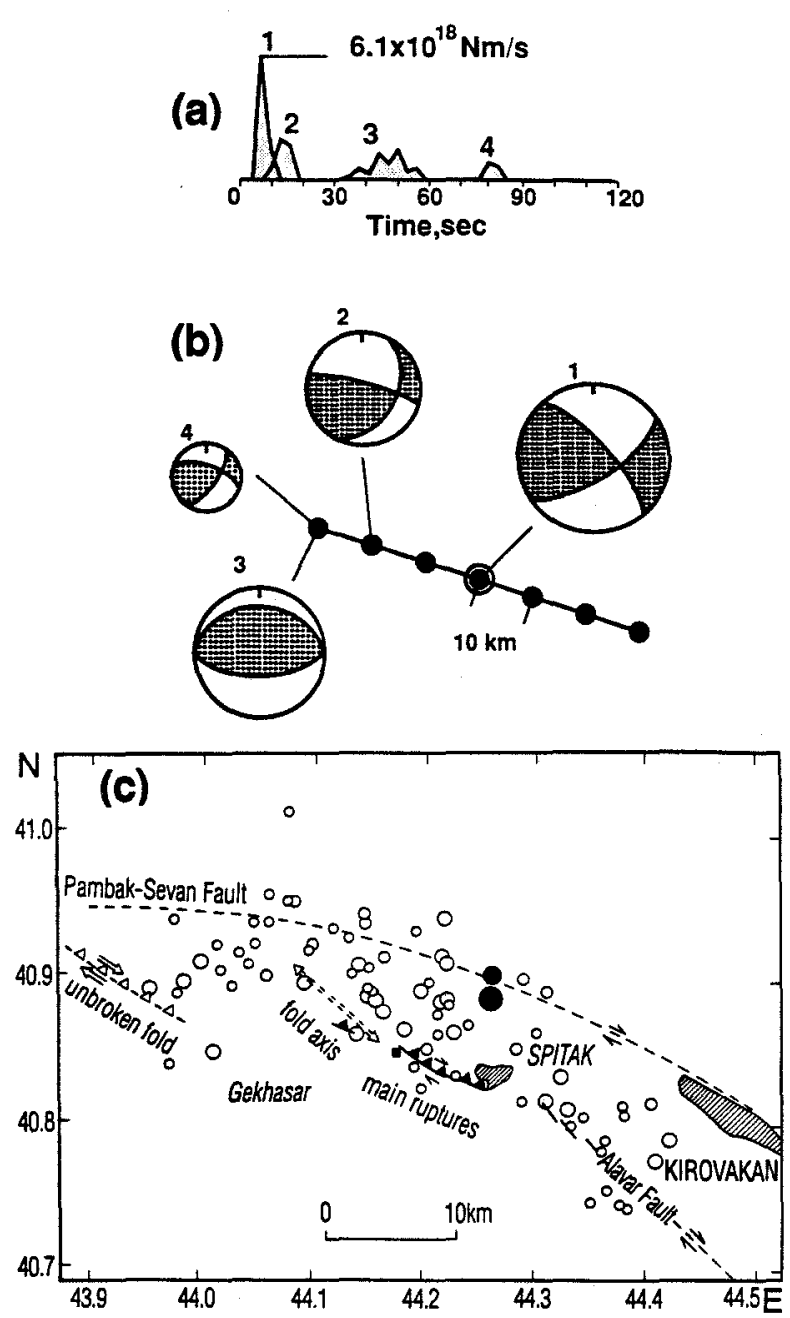

Fig. 9. Final solution of the inversion using ANMO data set and a base system of double-couple elements. (a) The source time function for each subevent is redetermined using narrow triangle time functions. (b) The radius of the mechanism diagrams is proportional to the seismic moment. (c) Simplified map showing major tectonic features and early aftershocks shown by circles. The solid circles indicate the mainshock and the largest aftershock [Dorbath et al., 1992].

Considering the heterogeneous instrument responses, we used only stations equipped with Streckeisen (STS) seismographs. They are COL (azimuth $5^{\circ}$ ), HIA $\left(54^{\circ}\right)$, WMQ $\left(70^{\circ}\right)$, KMI $\left(89^{\circ}\right), \operatorname{CTAO}\left(98^{\circ}\right)$, HRV $\left(317^{\circ}\right)$, PAS $\left(345^{\circ}\right)$, and $\mathrm{KEV}\left(348^{\circ}\right)$. The result of the CMT inversion is summarized in Table 4. The nondouble-couple component $\varepsilon$ is 0.36 , which indicates a large nondouble-couple component. The nondouble-couple component determined from long-period surface waves is larger than that from body waves. One possible explanation for this difference is that the spatial extent of subevent distribution is taken into account in the body wave inversion, while it is not in the CMT analysis. The CMT solution reported by Dziewonski et al. [1989] is also shown in Table 4. Our solution is similar to theirs except for the two components $M_{r f}$ and $M_{r q}$, that are very difficult to determine for shallow earthquakes. The total scalar moment, $1.47 \times 10^{19} \mathrm{~N} \mathrm{~m}\left(M_{w}=6.7\right)$ obtained from the body wave analysis is in good agreement with that of the CMT solution, $M_{0}=1.55 \times 10^{19} \mathrm{~N} \mathrm{~m}$.

Using the aftershock area, about $300 \mathrm{~km}^{2}$, we obtain the average stress drop as

$$
\Delta \sigma=2.5 M_{0} / S^{1.5}=7.5 \mathrm{MPa}
$$

which is comparable to the typical value of $10 \mathrm{MPa}$ for intraplate earthquakes. In (5) the numerical factor 2.5 for an elliptical crack model with an aspect ratio of 2 is used. (A value of 2.4 is usually used for a circular crack model.)

We can estimate the "local" stress drop of each subevent by substituting the seismic moment and the rupture area for each event into (5). For rough estimation, we used the average of fault areas corresponding to bilateral rupture and unilateral rupture. The fault area is then given by $S=(v t)^{2}$ where $v$ is the rupture velocity, assumed $2 \mathrm{~km} / \mathrm{s}$, and $\mathrm{t}$ is half the rupture duration. Then, using $M_{0}=7.57 \times 10^{18} \mathrm{~N} \mathrm{~m}$, $S=\left(2 \times 4.5 \times 10^{3}\right)^{2} \mathrm{~m}^{2}$ for the first subevent, we obtained $\Delta \sigma=26 \mathrm{MPa}$. Similarly, we determined $\Delta \sigma$ for the other subevents. The results are given in Table 3 . We see that the stress drop associated with the late event (subevent 3 ), $0.7 \mathrm{MPa}$, is unusually low. Since the rupture velocity may vary from event to event and the stress drop estimates are proportional to $v^{-3}$, this estimate has a large uncertainty. Nevertheless, in view of this low stress drop, we will call this event an after-slip event in the following discussion.

\section{DISCUSSION}

Subevents 1 and 2 shown in Figures $9 a$ and $9 b$ occurred during the first $20 \mathrm{~s}$. The mechanism of these two events combined is essentially the same as that obtained by Pacheco et al. [1989], but our scalar moment is about $20 \%$ smaller than theirs. The difference is probably due to the difference in the near-receiver structure used in these studies. Pacheco et al.'s [1989] solution indicates a distinct dip-slip subevent (event 1), while our solution shows a more strikeslip mechanism. This difference is mainly due to the difference in the way the rupture sequence is divided into subevents. If we take the composite mechanism, the difference is relatively small.

Haessler et al. [1992] made a forward modeling of the rupture process with five-segment sources diring the first $15 \mathrm{~s}$; three of them are dip-slip and two are strike-slip. Although the mechanisms of their individual subevents are somewhat different from those of ours, the composite mechanism of our subevents 1 and 2 is similar to their result.

TABLE 3. Source Parameters for the Final Solution

\begin{tabular}{|c|c|c|c|c|c|c|c|c|}
\hline No & Time, s & Distance, $\mathrm{km}$ & Depth, km & Moment, $10^{18} \mathrm{~N} \mathrm{~m}$ & Strike, deg & Dip, deg & Slip, deg & $\Delta \sigma, \mathrm{MPa}$ \\
\hline 1 & $4-13$ & 0 & 7.5 & 7.57 & 319 & $\overline{73}$ & 155 & 26 \\
\hline 2 & $7-19$ & 20 & 7.5 & 4.29 & 286 & 81 & 131 & 6.2 \\
\hline 3 & $32-59$ & 30 & 10.0 & 5.61 & 89 & 60 & 88 & 0.7 \\
\hline 4 & $73-85$ & 30 & 12.5 & 1.59 & 290 & 61 & 152 & 2.3 \\
\hline & & & & 14.7 & 302 & 59 & 143 & 7.5 \\
\hline
\end{tabular}




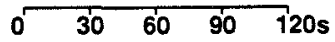

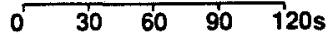

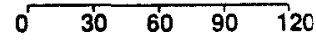

${ }_{5.3}^{\mathrm{COL}} \mathrm{UD}$

22.66

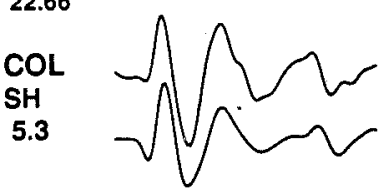

${ }_{53.6}^{\mathrm{HIA}}$ UD

62.62

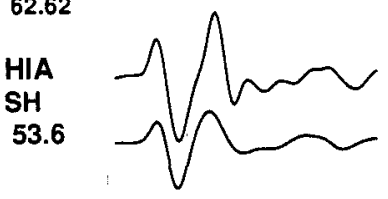

${ }_{60.4}^{3.36}$ UD
$\mathrm{INU}_{60.4}^{26.41}$

3.94

${ }_{65.6}^{B .94}$ UD

52.41

B.J

$\underset{70.1}{W .53} \sqrt{\text { WMQ UD }} \rightarrow$

56.62

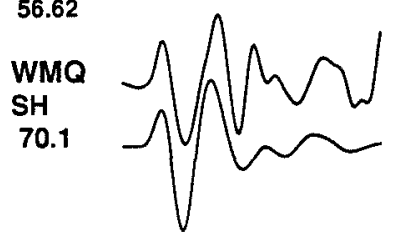

$\underset{72.8}{\text { GUMO }}$

4.35

${ }_{75.8}^{\mathrm{LZH}} \mathrm{UD} N$

33.07

$\underset{\mathrm{SH}}{\mathrm{LZH}} \leadsto$

4.10

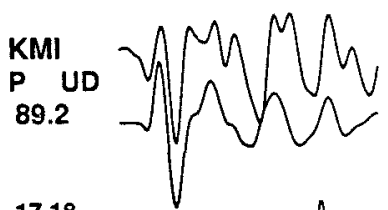

17.18

${ }_{S \mathrm{KMI}}^{\mathrm{M}} \mathrm{N} \mathrm{M}$

$89.2 \Omega$

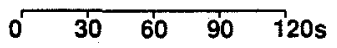

$\begin{array}{lllll}0 & 30 & 60 & 90 & 120 s\end{array}$

$0 \longdiv { 3 0 } 6 0 \quad 9 0 \quad 1 2 0$

5.45

CHTO
UD $98.4-\sqrt{3}$

3.67

$\underset{195.4}{\text { SLR UD }}-1$ M

11.69

$\mathrm{SH}_{195.4}^{\mathrm{SLR}}$

$\underset{284.5}{\mathrm{TOL}} \mathrm{N.28} \wedge \mathrm{N}$

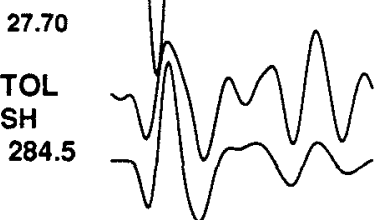

$\underset{317.3}{\text { URV }}$

31.61

$\underset{317.3}{\mathrm{HRV}}$

4.21

${ }_{319.7}^{\text {SCP }} \wedge$ ND

${ }_{319.7}^{20.83}$

${ }_{334.5}^{\mathrm{GDH}}$
$\underset{334.5}{\mathrm{GDH}}$

1.43

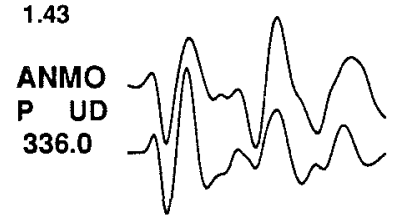

17.81

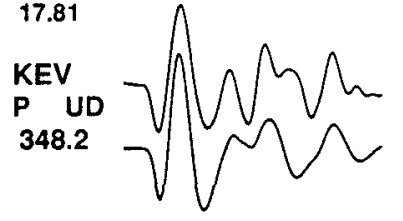

3.01

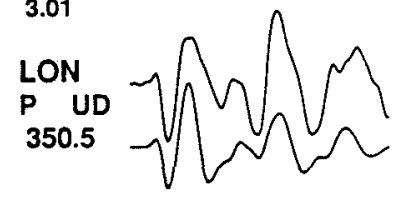

Fig. 10. Comparison of the observed records (upper trace) with synthetics (lower trace) for the solution shown in Figure 9. 
TABLE 4. Centroid Moment Tensor Solution

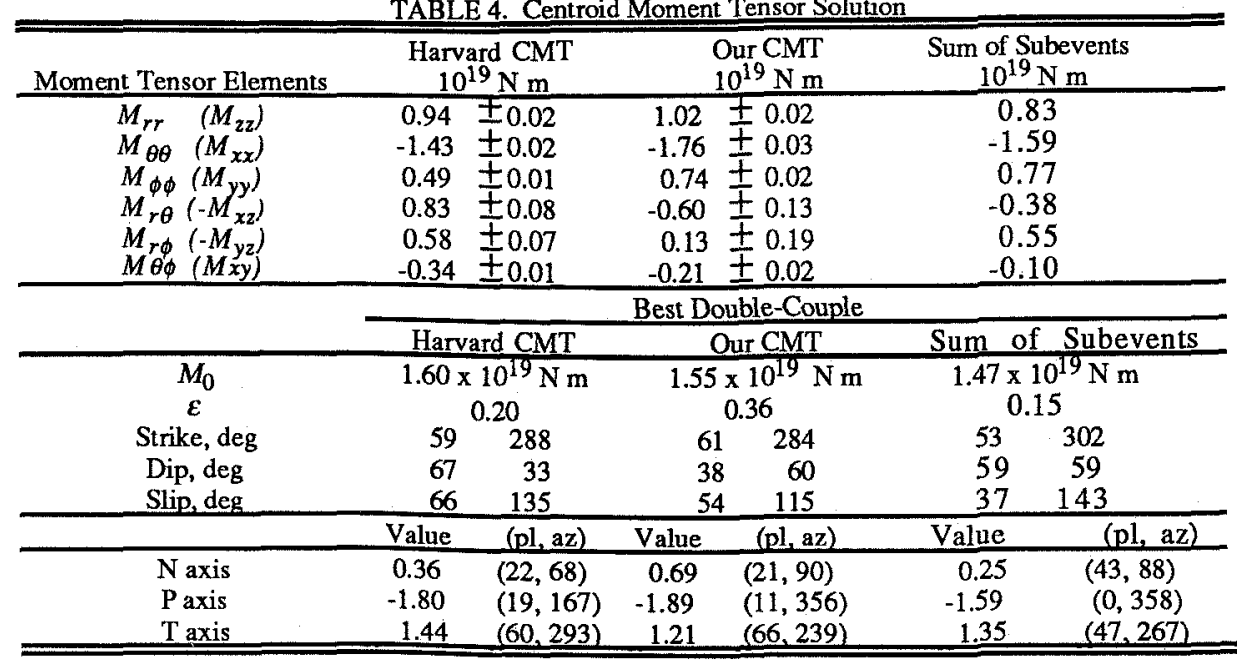

CMT is centroid moment tensor. $M_{x x}$ etc. are defined by Kanamori and Given [1981]. Value is the dipole moment in $10^{19} \mathrm{Nm}$ of $\mathrm{N}, \mathrm{P}$, and $\mathrm{T}$ axes; pl and az are plunge and azimuth in $\operatorname{deg}$ of $\mathrm{N}, \mathrm{P}$, and $\mathrm{T}$ axes.

Our subevent 3 which occurred about $30 \mathrm{~s}$ after the onset has not been reported before, because all the previous work is concerned with the source process during the initial $30 \mathrm{~s}$ only. This event is dip-slip with a north-south compression axis. Because of its thrust mechanism, subevent 3 has much smaller $S H$ to $P$ ratio than subevents 1 and 2 , which are primarily strike-slip, and was not obvious on the $S H$ component. The $S H$ wave seismograms are thus much simpler than the $P$ wave seismograms. Our subevent 4 has a right-lateral mechanism on the NW-SE trend similar to subevents 1 and 2 .

The tectonic framework of the source region of the Armenian earthquake has been thoroughly discussed by Cisternas et al. [1989], Philip et al. [1989, 1992], Dorbath [1992] and Haessler et al. [1992]. Here we use Figure 9c, taken from Dorbath et al. [1992], to interpret our subevent sequence.

The source region of the Armenian earthquake is located within the ESE-WNW oriented Pambak-Sevan fold and thrust belt in the southern front of the Lesser Caucasus. The southeastern segment, the Alavar fault, is oriented in $\mathrm{N} 140^{\circ} \mathrm{E}$ with primarily strike slip movement. Adjacent to the northwest end of this segment is the main branch between Spitak and Gekhasar with a general orientation of $\mathrm{N} 120^{\circ} \mathrm{E}$. This branch has reverse faulting dipping to the north with a right-lateral component. The aftershock distribution shows even more clearly the existence of dipslip faulting. Dorbath et al. [1992] identified five segments of aftershock activity and found that the main surface ruptures correlate well with the aftershocks on an $\mathrm{N} 120^{\circ} \mathrm{E}$ trend, dipping $50^{\circ}$ to the $\mathrm{NE}$, and with thrust and rightlateral components. Field observations support that both right-lateral and thrust faulting occurred during the Spitak earthquake. Philip et al. [1992] show that the southeast branch consists of a right-lateral strike-slip and the main branch indicates a reverse faulting dipping to the north.

Our subevents 1 and 2 represent the composite radiation pattern from the right-lateral slip on the southeast branch and the thrust faulting on the main branch.

Our subevent 3 is located to the west of the main segment. The mechanism and location of this event are similar to those of subevent 3 of Haessler et al. [1992]. However, our event occurred much later ( $30 \mathrm{~s}$ after the onset) and is about 6 times larger in moment. Another interesting feature of subevent 3 is a longer source duration, or slow moment release rate. The contrast of the moment release rates between subevents 1 and 3 is clearly seen in the moment rate function shown in Figure $9 a$. As shown in Figure $9 c$, our subevent 3 probably occurred in the area characterized by active folds [Dorbath et al., 1992] it may have occurred on one of the blind faults mentioned by Dorbath et al. [1992]. The mechanism, the delay from the main sequence, and the slow source process suggest that this event is a slow after-slip event which released, after the main rupture was completed, the north-south tectonic stress in a complex, possibly weak, structure beneath the geologically young fold.

Our subevent 4 is very similar in location and mechanism to subevent 4 of Haessler et al. [1992] However, it occurred very late in the sequence ( $70 \mathrm{~s}$ after the origin time) and can be considered as another after-slip event.

The results summarized above suggest that in a region where both strike-slip and crustal shortening are taking place, like the Caucasus and southern California, a large strike-slip event may accompany large thrust events, and vice versa. If the later events occur during the complex rupture sequence of the main event, they may escape notice by casual inspection of data. In order to determine the total coseismic deformation pattern, it is essential to resolve these multiple events in time, space, and mechanism. Although the evidence for subevent 3 was suggested by preliminary inspection of the observed records, quantitative estimation of the source parameters for this event was made possible only with the inversion method used in this study. The combined use of both $P$ and $S H$ waves proved very useful to stabilize the solutions when the subevent mechanisms were allowed to change.

The existence of the after-slip event with a mechanism different from the first two events is supported by a large nondouble-couple component obtained by surface-wave analysis. The CMT solution obtained from long-period surface waves reveals a large nondouble-couple component 

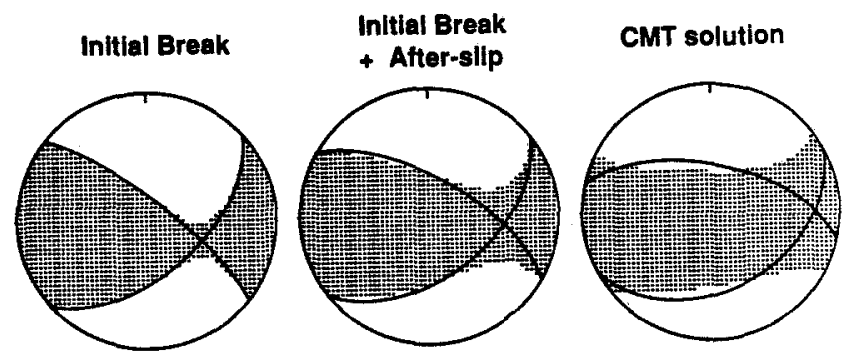

Fig. 11. Tensor sum of the final solution is compared with the centroid moment tensor (CMT) solution derived from long-period surface waves. The leftmost figure shows the tensor sum of the first two subevents shown in Figure 9.

(Table 4). Figure 11 compares the CMT solution with the tensor sum of the four subevents determined in the present study. Both of them show a similar nondouble-couple mechanism. In contrast, the tensor sum of the first two subevents does not exhibit such a large nondouble-couple component. This result supports the conclusion that the dip-slip faulting mainly occurred during $30-60 \mathrm{~s}$ after the initial break.

A similar interpretation of nondouble-couple mechanisms has been made by other investigators [e.g. Ekström and Dziewonski, 1985; Kuge and Kawakatsu, 1990]. Recent analyses of large events indicate mechanism changes during the rupture process. Examples are the 1968 Borrego Mountain earthquake [Burdick and Mellman, 1976], the 1976 Tangshan earthquake [Kikuchi and Kanamori, 1986; Nábělek et al., 1987], and the 1976 Guatemala earthquake [Kikuchi and Kanamori, 1991]. Thus mechanism changes appear to be relatively common and important aspects of large earthquakes.

Acknowledgments. We thank Hitoshi Kawakatsu for comments on the nondouble-couple component of the CMT solution. This research was partially supported by U.S. Geological Survey grant 1434-93-G2305, and Grant-In-Aid for Scientific Research 02201106 from the Ministry of Education, Japan. This is contribution 5139, Division of Geological and Planetary Sciences, California Institute of Technology, Pasadena, Califomia.

\section{REFERENCES}

Bouchon, $M$., Teleseismic body wave radiation from a seismic source in a layered medium, Geophys. J. R. Astron. Soc., 47, 515-530, 1976.

Burdick, L. J., and G. R. Mellman, Inversion of the body waves from the Borrego Mountain earthquake to the source mechanism, Bull. Seismol. Soc. Am., 66, 1485-1499, 1976.
Cisternas, A., et al., The Spitak (Armenia) earthquake of 7 December 1988: field observations, seismology and tectonics, Nature, 339, 675$679,1989$.

Dorbath, L., C. Dorbath, L. Rivera, H. Fuenzalida, A. Cisternas, R. Tatevossian, J. Aptekman, and S. Arefiev, Geometry, segmentation and stress regime of the Spitak (Armenia) earthquake from the analysis of the aftershock sequence, Geophys. J. Int., 108, 309-328, 1992.

Dziewonski, A. M., G. Ekström, J. H. Woodhouse, and G. Zwart, Centroid-moment tensor solutions for October-December 1988, Phys. Earth Planet. Inter., 57, 179-191, 1989.

Ekström, G., and A. M. Dziewonski, Centroid-moment tensor solutions for 35 earthquakes in Western North America (1977-1983), Bull. Seismol. Soc. Am., 75, 23-39, 1985.

Haessler, H., A. Deschamps, H. Dufumier, H. Fuenzalida, and A. Cisternas, The rupture process of the Armenian earthquake from broad-band teleseismic body wave records, Geophys. J. Int., 109, 151-161, 1992.

Haskell, N. A., Crustal reflection of plane $S H$ waves, J. Geophys. Res., $65,4147-4150,1960$.

Haskell, N. A., Crustal reflection of plane $P$ and $S V$ waves, J. Geophys. Res., 67, 4751-4767, 1962.

Jeffreys, H., and K. E. Bullen, Seismological tables, Office of the British Association, Burlington House, London, 1958.

Kanamori, H., and J. W. Given, Use of long-period surface waves for rapid determination of earthquake source parameters, Phys. Earth Planet.Inter., 27, 8-31, 1981.

Kikuchi, M., and H. Kanamori, Inversion of complex body waves-II, Phys. Earth Planet. Inter, 43, 205-222, 1986.

Kikuchi, M., and H. Kanamori, Inversion of complex body waves-III, Bull. Seismol. Soc. Am., 81, 2335-2350, 1991.

Kuge, K, and H. Kawakatsu, Analysis of a deep "nondouble couple" earthquake using very broadband data, Geophys. Res. Lett., 17, 227. $230,1990$.

Nábělek, J., W.-P. C. Chen, and H. Ye, The Tangshan earthquake sequence and its implications for the evolution of the North China basin, J. Geophys. Res., 92, 12615-12628, 1987.

Pacheco, J. F., C. H. Estabrook, D. W. Simpson, and J. L. Nábĕlek, Teleseismic body wave analysis of the 1988 Armenian earthquake, Geophys. Res. Lett., 16, 1425-1428, 1989.

Philip, H., A. Cisternas, A. Gvishiani, and A. Gorshkov, The Caucasus: an actual example of the initial stages of continental collision, Tectonophysics, 161, 1-21, 1989.

Philip, H., E. Rogozhin, A. Cistemas, J. C. Bousquet, B. Borisov, and A. Karakhanian, The Armenian earthquake of 1988 December 7: faulting and folding, neotectonics and palaeoseismicity, Geophys. $J$. Int., 110, 141-158, 1992.

H. Kanamori, California Institute of Technology, Seismological Lab 252-21, Pasadena, CA 91125.

M. Kikuchi, Department of Physics, Yokohama City University, Yokohama 236, Japan.

K. Satake, Department of Geological Sciences, University of Michigan, Ann Arbor, MI 48109.

(Received April 23, 1992; revised June 1, 1993; accepted June 8, 1993.) 